\title{
Fuzzy Nominating Technique to Determine Fuzzy Preference Index of a Player in Kabaddi
}

\author{
Sk Sabir Ali ${ }^{1}$, Samirranjan Adhikari ${ }^{2}$, Saikot Chatterjee ${ }^{3}$ \\ ${ }^{I}$ Assistant Teacher, Ajangachi High Madrasah, Kashmoli, Howrah, and Research Scholar, Department of \\ Physical Education, University of Kalyani, Kalyani, Nadia, West Bengal, India. \\ ${ }^{2}$ Assistant Professor in Psychology, Shimurali Sachinandan College of Education, Shimurali, Nadia, West \\ Bengal, India \\ ${ }^{3}$ Assistant Professor, Department of Physical Education, University of Kalyani, Kalyani, Nadia, West Bengal, \\ India. Assistant Professor, Department of Physical Education, University of Kalyani, Kalyani, Nadia, West \\ Bengal, India.
}

\begin{abstract}
:
Objectives: Nominating technique is commonly applied for studying social choices and rejections. Sociometry is one type of nominating technique. It also acts as a powerful tool for assessing dynamics and development in groups devoted to therapy or training.

Method: To construct preference matrix a sociometric test was administered on the 12 players of a Kabaddi team. By tabulating the value of nomination in order of preference (1 to 5), as exercised by an individual member a Preference Matrix was formed; a row of the Preference Matrix represents the preference exercised by an individual member and a column represents the preference received by an individual member. This matrix was then transformed in to a Fuzzy Preference Matrix. Fuzzy Preference Index of an individual player was calculated by taking the total of the corresponding column of the matrix.
\end{abstract}

Results: The popularity of each of the players was calculated.

Conclusion: This is a nominating technique based on democratic method.

Key words: Nominating Technique, Sociometry, Fuzzy Number

\section{Nominating Technique}

In nominating technique, each person names or nominates other persons, events, objects, subject matter, which is perceived as fitting into certain categories or situations. The technique is commonly applied for studying social choices and rejections.

"Sociometry" is one type of nominating technique. Sociometry is a way of measuring the degree of social relatedness among people in a group. Jacob Levy Moreno has coined the term sociometry. Sociometry was developed by Jacob L. Moreno $(\mathbf{1 9 3 4}, \mathbf{1 9 6 0})$ in the 1930s and became closely associated with small group research and a focus on interpersonal choices. "Sociometry" may be broadly defined as a method of discovering and evaluating group structure, social status and personality traits through measuring the acceptance or rejection between individuals in a group.

A useful working definition of sociometry is that it is a methodology for tracking the energy vectors of interpersonal relationships in a group. It shows the patterns of how individual members in a group associate with each other when motivating together as a group toward a specified end or goal (Criswell in Moreno, 1960).

Moreno defined sociometry as the mathematical study of psychological properties of populations, the experimental technique of and the results obtained by application of quantitative methods (Moreno, 1934, Revised edition 1953). Thus, it is a technique of evaluating interpersonal relationship in a group.

Stanley \& Hopkins (1972) have defined Sociometry as "the study of interrelationship among members of a group, that is, its social structure: how each individual is perceived by the group".

With the help of sociometric technique the data relating to the choice, communication and interaction patterns of individuals in a group are gathered and analyzed (Kerlinger, 1973, 1986).

Whenever a group of individuals come forward with a common mission, they make choices - where to sit or stand; choices about who is perceived as friendly and who not, who is central to the group, who is rejected and who is isolated. Sociometry is because individuals make choices in interpersonal relationships. Moreno says, "Choices are fundamental facts in all ongoing human relations, choices of people and choices of things. It is immaterial whether the chooser knows the motivations or not - it is immaterial whether the choices are inarticulate or highly expressive, whether rational or irrational. They do not require any special justification as long as they are spontaneous and true to the self of the chooser. They are facts of the first existential order." (Moreno, 1934, Revised edition 1953, p. 720). 


\section{Use of Nominating Technique}

Measurement of social and emotional relatedness can be useful not only in the context of assessment of behaviour within a group, but also for interventions to bring about positive change in the desired direction and for determining the extent of change takes place as a result of these interventions. As sociometry allows the group to see itself objectively and to analyze its own dynamics, so, for a work group, it can be a powerful tool for reducing conflict and improving interpersonal communication. It also acts as a powerful tool for assessing dynamics and development in groups devoted to therapy or training.

\section{Sociometric Criteria}

There are always some bases or criteria in choice making process. The criteria may be subjective, such as an intuitive feeling of liking or disliking a person on first impression; these also may be more objective and conscious, such as knowing that a person does or does not have certain skills needed for the group task.

When members of a group are asked to choose others in the group based on specific criteria, everyone in the group can make choices and describe why the choices were made. From these choices a description emerges of the networks inside the group. A drawing, like a map, of those networks is called a socio-gram. The data for the socio-gram may also be displayed as a table or matrix of each member's choices. Such a table is called a socio-matrix.

\section{Some Principles of Criterion Selection}

i) The criterion should be as simply stated and as straightforward as possible.

ii) The respondents should have some actual experience in reference to the criterion, whether ex post facto or present, otherwise the questions will not arise any significant response.

iii) The criterion should be specific rather than general or vague. Vaguely defined criteria evoke vague responses.

iv) When possible, the criterion should be actual rather than hypothetical.

v) A criterion is more powerful if it is one that has a potential for being acted upon. For example, for incoming college freshmen the question "Whom would you choose as a roommate for the year?" has more potential of being acted upon than the question "Whom do you trust?"

vi) Moreno points out that the ideal criterion is one that helps further the life-goal of the subject. Helping a college freshman select an appropriate roommate is an example of a sociometric test that is in accord with the life-goal of the subject.

vii) As a rule questions should be future oriented, imply how the results are to be used, and specify the boundaries of the group (Hale, 1985).

viii) And last, but not least, the criteria should be designed to keep the level of risk for the group appropriate to the group's cohesion and stage of development.

\section{Validity of Sociometry}

Jane Mouton, Robert Blake and Benjamin Fruchter reviewed the early applications of sociometry and concluded that the number of sociometric choices do tend to predict such performance criteria as productivity, combat effectiveness, training ability, and leadership. An inverse relationship also holds: the numbers of sociometric choices received are negatively correlated with undesirable aspects of behaviour such as accidentproneness, sick bay attendance and frequency of disciplinary charges (Mouton, Blake \& Fruchter in Moreno, 1960).

One study found a significant positive correlation between group sociometric cohesion and field performance of small military combat units (Goodacre \& Daniel in Moreno, 1960).

Sociometric ratings by co-workers for desirability as work partners and other job related activities correlate with positive attitudes toward work and with quality and quantity of performance on the job (Springer, 1953; Van Zelst, 1951).

Accident proneness is inversely correlated with sociometric choices received (Speroff \& Kerr, 1952; Fuller \& Baune, 1951; Zeleny, 1947).

Consistent with these findings about safety are studies in military settings which show that flight accidents, frequency of sick bay attendance, and number of disciplinary offences are negatively related with the number of sociometric choices received when the criterion measures a positive aspect of behaviour (Zeleny, 1947; French, 1951).

A study of leadership showed that when leaders were chosen by sociometric procedures, their groups were more efficient than when members not seen as leaders were assigned that role (Rock \& Hay, 1953).

A study of navy pilots suggested that low morale and cliques may result when the official leader is not a sociometric star (Jenkins, John G. in Moreno, 1960 pp. 560 - 567). Another study of choices of playmates in 
fourth-grade children showed a high correlation between the choices children made on the sociometric test and the choices children made in actual play (Byrd, 1946).

\section{Construction of Preference Matrix}

To construct preference matrix a sociometric test was administered on the players of a Kabaddi team. The instruction (criteria) was - "According to your preference, write the name of five" of your team-mates with whom you want to enjoy your leisure time. Your response will be kept in strict confidence and this will be used for the research purpose only."

By tabulating the value of nomination in order of preference (1 to 5), as exercised by an individual member a "Preference Matrix" was formed which is shown in table-1. A row of the "Preference Matrix" represents the preference exercised by an individual member and a column represents the preference received by an individual member. The blank cells of "Preference Matrix" were supposed to contain integers greater than 5.

Table - 1: Preference Matrix of the University Level Kabaddi Players ${ }^{2}$

\begin{tabular}{|c|l|l|l|l|l|l|l|l|l|l|l|l|}
\hline Player No. $^{3}$ & $\mathbf{1}$ & $\mathbf{2}$ & $\mathbf{3}$ & $\mathbf{4}$ & $\mathbf{5}$ & $\mathbf{6}$ & $\mathbf{7}$ & $\mathbf{8}$ & $\mathbf{9}$ & $\mathbf{1 0}$ & $\mathbf{1 1}$ & $\mathbf{1 2}$ \\
\hline $\mathbf{1}$ & & & & 1 & 4 & 2 & 5 & & & & & 3 \\
\hline $\mathbf{2}$ & 1 & & 4 & & & & 3 & & & 2 & & 5 \\
\hline $\mathbf{3}$ & & 3 & & & & & & & 1 & 2 & 5 & 4 \\
\hline $\mathbf{4}$ & & & & & & 1 & 4 & 3 & 2 & & & 5 \\
\hline $\mathbf{5}$ & & & & 3 & & 2 & & 4 & & 5 & 1 & \\
\hline $\mathbf{6}$ & & & & 1 & 4 & & 3 & 5 & & 2 & & \\
\hline $\mathbf{7}$ & & & & 4 & & 1 & & 3 & 5 & 2 & & \\
\hline $\mathbf{8}$ & & & & 2 & & 1 & 4 & & 5 & 3 & & \\
\hline $\mathbf{9}$ & & & 1 & & & 5 & & & & 4 & 3 & 2 \\
\hline $\mathbf{1 0}$ & 4 & & & 2 & & 5 & 1 & & 3 & & & \\
\hline $\mathbf{1 1}$ & & & & 5 & & & 3 & 4 & 1 & & & 2 \\
\hline $\mathbf{1 2}$ & 1 & & 4 & 3 & & 5 & & & & & 2 & \\
\hline
\end{tabular}

From table- 1 it is clear that player- 1 put his $1^{\text {st }}$ preference to $4,2^{\text {nd }}$ preference to $6,3^{\text {rd }}$ preference to 12 , $4^{\text {th }}$ preference to 5 and $5^{\text {th }}$ preference to 7 , and so on.

\section{Construction of Fuzzy Preference Matrix}

A "Fuzzy Preference Matrix" was formed which is shown in table-2. In course of converting a preference value to a fuzzy number ${ }^{4}$, following membership function was used:
a)
$\mu(\mathrm{x})=1$;
for $\mathrm{x}<1$
b)
$\mu(\mathrm{x})=(5-\mathrm{x}) /$
$(5-1) ;$ for $1 \leq x \leq 5$
for $\mathrm{x}>5$

It is clear that when -

$$
\begin{aligned}
& \mathrm{x}=1 \text { then } \mu(\mathrm{x})=(5-1) /(5-1)=4 / 4=1.00 \\
& \mathrm{x}=2 \text { then } \mu(\mathrm{x})=(5-2) /(5-1)=3 / 4=0.75 \\
& \mathrm{x}=3 \text { then } \mu(\mathrm{x})=(5-3) /(5-1)=2 / 4=0.50 \\
& \mathrm{x}=4 \text { then } \mu(\mathrm{x})=(5-4) /(5-1)=1 / 4=0.25 \\
& \mathrm{x}=5 \text { then } \mu(\mathrm{x})=(5-5) /(5-1)=0 / 4=0.00
\end{aligned}
$$

As any player could not put his franchise to himself so, the diagonal cells were filled in by zeros.

\footnotetext{
${ }^{1}$ Psychological experiments have shown that human beings cannot simultaneously compare more than seven objects (plus or minus two) (Miller, 1956). This is the rational of considering five alternatives in this study.

${ }^{2}$ For example the Preference Matrix of Burdwan University Kabaddi Team is shown here.

${ }^{3}$ For ethical purpose, we did not disclose the name of the members of the team and so not to disclose the nominating pattern of the members instead of writing their names, members of the group were symbolized by numbers.

${ }^{4}$ Fuzzy number - In the real world, the data sometimes cannot be recorded or collected precisely. For instance, the water level of a river cannot be measured in an exact way because of the fluctuation and the temperature in a room also can not be measured precisely because of a similar reason. Therefore fuzzy numbers provide formalized tools to deal with non-precise quantities possessing non-random imprecision or vagueness. Thus a more appropriate way to describe the water level is to say that the water level is "around 25 meters". The phrase "around 25 meters" can be regarded as a fuzzy number, which is usually denoted by the capital letter A. Zadeh in (1965) introduced the concept of fuzzy set and its applications. In Dubois and Prade (1978) introduced the notion of fuzzy real numbers and established some of their basic properties. Goetschel and Voxman (1986) introduced new equivalent definition of fuzzy numbers using the parametric representation.
} 
Table - 2: Fuzzy Preference Matrix of the University Level Kabaddi Players 5

\begin{tabular}{|c|c|c|c|c|c|c|c|c|c|c|c|c|}
\hline Player No. & $\mathbf{1}$ & $\mathbf{2}$ & $\mathbf{3}$ & $\mathbf{4}$ & $\mathbf{5}$ & $\mathbf{6}$ & $\mathbf{7}$ & $\mathbf{8}$ & $\mathbf{9}$ & $\mathbf{1 0}$ & $\mathbf{1 1}$ & $\mathbf{1 2}$ \\
\hline $\mathbf{1}$ & 0.00 & 0.00 & 0.00 & 1.00 & 0.25 & 0.75 & 0.00 & 0.00 & 0.00 & 0.00 & 0.00 & 0.50 \\
\hline $\mathbf{2}$ & 1.00 & 0.00 & 0.25 & 0.00 & 0.00 & 0.00 & 0.50 & 0.00 & 0.00 & 0.75 & 0.00 & 0.00 \\
\hline $\mathbf{3}$ & 0.00 & 0.50 & 0.00 & 0.00 & 0.00 & 0.00 & 0.00 & 0.00 & 1.00 & 0.75 & 0.00 & 0.25 \\
\hline $\mathbf{4}$ & 0.00 & 0.00 & 0.00 & 0.00 & 0.00 & 1.00 & 0.25 & 0.50 & 0.75 & 0.00 & 0.00 & 0.00 \\
\hline $\mathbf{5}$ & 0.00 & 0.00 & 0.00 & 0.50 & 0.00 & 0.75 & 0.00 & 0.25 & 0.00 & 0.00 & 1.00 & 0.00 \\
\hline $\mathbf{6}$ & 0.00 & 0.00 & 0.00 & 1.00 & 0.25 & 0.00 & 0.50 & 0.00 & 0.00 & 0.75 & 0.00 & 0.00 \\
\hline $\mathbf{7}$ & 0.00 & 0.00 & 0.00 & 0.25 & 0.00 & 1.00 & 0.00 & 0.50 & 0.00 & 0.75 & 0.00 & 0.00 \\
\hline $\mathbf{8}$ & 0.00 & 0.00 & 0.00 & 0.75 & 0.00 & 1.00 & 0.25 & 0.00 & 0.00 & 0.50 & 0.00 & 0.00 \\
\hline $\mathbf{9}$ & 0.00 & 0.00 & 1.00 & 0.00 & 0.00 & 0.00 & 0.00 & 0.00 & 0.00 & 0.25 & 0.50 & 0.75 \\
\hline $\mathbf{1 0}$ & 0.25 & 0.00 & 0.00 & 0.75 & 0.00 & 0.00 & 1.00 & 0.00 & 0.50 & 0.00 & 0.00 & 0.00 \\
\hline $\mathbf{1 1}$ & 0.00 & 0.00 & 0.00 & 0.00 & 0.00 & 0.00 & 0.50 & 0.25 & 1.00 & 0.00 & 0.00 & 0.75 \\
\hline $\mathbf{1 2}$ & 1.00 & 0.00 & 0.25 & 0.50 & 0.00 & 0.00 & 0.00 & 0.00 & 0.00 & 0.00 & 0.75 & 0.00 \\
\hline $\mathbf{F P I}$ & $\mathbf{2 . 2 5}$ & $\mathbf{0 . 5 0}$ & $\mathbf{1 . 5 0}$ & $\mathbf{4 . 7 5}$ & $\mathbf{0 . 5 0}$ & $\mathbf{4 . 5 0}$ & $\mathbf{3 . 0 0}$ & $\mathbf{1 . 5 0}$ & $\mathbf{3 . 2 5}$ & $\mathbf{3 . 7 5}$ & $\mathbf{2 . 2 5}$ & $\mathbf{2 . 2 5}$ \\
\hline
\end{tabular}

\section{Determination of Fuzzy Preference Index (FPI)}

Column total of the fuzzy preference matrix was calculated to determine FPI of each individual member of the group. Player number 1, 2, 3, 4, 5, 6, 7, 8, 9, 10, 11 and 12 had the fuzzy preference indices of $2.25,0.50,1.50,4.75,0.50,4.50,3.00,1.50,3.25,3.75,2.25$ and 2.25 respectively. The player- 4 was the most popular among the team; whereas player- 2 and 5 had the lowest popularity.

\section{References}

[1]. Byrd, E. (1946). A Study of Validity and Constancy of Choices in a Sociometric Test. Sociometry. IX (2-3)

[2]. Dubois, D \& Prade, H. (1978). Operations on fuzzy numbers. International Journal of Systems Science, 9: 613-626.

[3]. French, R.L. (1951). Sociometric Status and Individual Adjustment among Naval Recruits. Journal of Abnormal Social Psychology, 46: 64 - 72

[4]. Fuller, E. M., and H. A. Baune, H.A. (1951). Injury-Proneness and Adjustment in a Second Grade. Sociometry, 14: 210 - 225

[5]. Goetschel, G. \& Voxman, W. (1986). Elementary Fuzzy Calculus. Fuzzy Set and Systems, 18: $31-43$.

[6]. Hale, A. E. (1985). Conducting Clinical Sociometric Explorations: A Manual. Roanoke. Virginia: Royal Publishing Company.

[7]. Kerlinger, F.N. (1973). Foundations of behavioural research. New York: Holt Rinehart and Winston, inc

[8]. Kerlinger, F.N. (1986). Foundations of behavioural research. New York: Holt Rinehart and Winston, inc

[9]. Moreno, J. L. (1934, Revised edition 1953). Who Shall Survive? Beacon, NY: Beacon House.

[10]. Moreno, J. L. (1960). The Sociometry Reader. Glencoe, Illinois: The Free Press.

[11]. Rock, M. L. and Hay, E.N. (1953). Investigation of the Use of Tests as a Predictor of Leadership and Group Effectiveness in a Job Evaluation Situation. Journal of Social Psychology, 38: 109 - 119.

[12]. Speroff, B., and Kerr, W. (1952). Steel Mill 'Hot Strip' Accidents and Interpersonal Desirability Values. Journal of Clinical Psychology, 8: 89-91.

[13]. Springer, D. (1953). Ratings of Candidates for Promotion by Co-workers and Supervisors. Journal of Applied Psychology, 37: 347-351.

[14]. Stanley, J.C. and Hopkins, K.D. (1972). Educational and psychological measurement and evaluation. Englewood Cliff, New Jersey: Prentice-Hall.

[15]. Van Zelst, R. H. (1951). Worker Popularity and Job Satisfaction. Personnel Psychology, 4: 405 - 412.

[16]. Zadeh, L.A. (1965). Fuzzy sets. Information Control, 8: 338-353.

[17]. Zeleny, L. D. (1947). Selection of Compatible Flying Partners. American Journal of Sociology, $52: 424$ - 431.

\footnotetext{
${ }^{5}$ For example the Fuzzy Preference Matrix of Burdwan University Kabaddi Team is shown.
} 